\title{
AVALIAÇÃO DO DESEMPENHO DE DISPOSITIVO DE CORTE DE BASE DE COLHEDORA DE CANA-DE-AÇÚCAR
}

\author{
JOSÉ V. SALVI ${ }^{1}$, MARCOS A. MATOS ${ }^{2}$, MARCOS MILAN ${ }^{3}$
}

\begin{abstract}
RESUMO: A utilização da colheita mecanizada na cana-de-açúcar faz surgir preocupações quanto à qualidade do corte e à perda de matéria-prima; para minimizar esses problemas, os fabricantes de colhedoras têm desenvolvido dispositivos para auxiliar o operador no controle da altura de corte. Em vista disso, o objetivo deste trabalho foi avaliar o desempenho qualitativo de um dispositivo semi-automático de controle de altura de corte basal, instalado em uma colhedora de cana picada. Analisou-se em duas situações, com e sem o uso do dispositivo, a variabilidade da altura de corte, tocos arrancados e impureza mineral, por meio de estatística descritiva. Para as condições analisadas, o corte de base não está sob controle estatístico, não sendo possível manter a altura de corte determinada pela usina. $\mathrm{O}$ uso do dispositivo pode ser útil para a manutenção de altura de corte menor, mas é influenciado pelo estado do canavial e não mostrou vantagens quanto à impureza mineral; no entanto, apresentou menor freqüência de tocos arrancados. Existem diferenças na altura do toco e na impureza mineral quando se considera o período de trabalho (manhã/tarde).
\end{abstract}

PALAVRAS-CHAVE: mecanização, colheita, controle de qualidade.

\section{EVALUATION OF THE PERFORMANCE OF A BASE CUTTING DEVICE OF A SUGAR CANE HARVESTER}

\begin{abstract}
The use of mechanized harvesting in sugar cane brings up some concerns related to cut quality and raw material losses. In order to minimize this problem, harvester producers have developed devices that help the operator to control the cutting height. Thus, this study aimed to evaluate the performance of a semi-automatic cutting control device at the base, fitted onto a chopped sugar cane harvester. The variability of the cutting height, removed stems' base and mineral impurities were analyzed. Under the studied conditions, the height of the base cut, with or without the use of the control device is not under statistical control, and the process can not meet the cutting height specification determined by the sugar mill. The use of the control device can be helpful to maintain a lower cutting height, but it is influenced by crop conditions and did not show any advantage regarding mineral impurities; however, it showed lower frequency of removed stems' bases. There are differences in stems' base height and mineral impurities when considering the period of working hours.
\end{abstract}

KEYWORDS: mechanization, harvest, quality control.

\section{INTRODUÇÃO}

No processo de produção da cana, a colheita destaca-se pelos altos custos envolvidos e dificuldades operacionais, seja ela conduzida de forma manual, semimecanizada, seja mecanizada. Nos últimos anos, a colheita tem passado por uma fase de substituição do corte manual para o mecanizado e, de acordo com NUNES JÚNIOR et al. (2005), 38,8\% da produção de cana da safra 2003-2004 da região Centro-Sul do País foi colhida mecanicamente e, dessas, 40,7\% na forma picada e crua. Existe a perspectiva de esses percentuais aumentarem nos próximos anos devido à possibilidade de redução de custos, escassez de mão-de-obra e pela legislação ambiental, que reduz gradativamente a queima de canaviais, inviabilizando a colheita manual.

\footnotetext{
${ }^{1}$ Eng ${ }^{0}$ Agrônomo, Mestre em Agronomia, ESALQ/USP, Fone: (OXX14) 3641-2745, jvsalvi@esalq.usp.br

${ }^{2}$ Eng $^{\circ}$ Agrônomo, Mestrando, PPG Máquinas Agrícolas, ESALQ/USP.

${ }^{3}$ Eng $^{\mathrm{O}}$ Agrônomo, Prof. Associado, ESALQ/USP, Piracicaba - SP.

Recebido pelo Conselho Editorial em: 6-7-2006
}

Aprovado pelo Conselho Editorial em: 20-12-2006 
Na colheita mecanizada de cana-de-açúcar, existem algumas peculiaridades relacionadas às interações solo-máquina-planta, que têm causado preocupações, como as perdas de cana no campo, a redução da qualidade da matéria-prima e a redução da longevidade do canavial. Um dos componentes da colhedora que originam esses problemas, é o cortador de base, que devido à deflexão e à deficiência no controle da altura de corte, provoca danos na soqueira, causando perdas de matéria-prima, diminuição da população de colmos e redução da qualidade tecnológica da cana colhida. As perdas são constituídas de massa deixada no campo, e a população de colmos é reduzida por duas maneiras: soqueiras destruídas ou removidas mecanicamente e por deterioração, devido aos danos por cisalhamento dos tocos, o que facilita o ataque de pragas e doenças. A cana colhida tem sua qualidade tecnológica reduzida, com o cortador de base, por rebolos fragmentados sujeitos a contaminação e a incorporação de terra, caso as lâminas dos discos dos cortadores trabalharem em contato ou abaixo da superfície do solo, e se o sistema radicular de soqueiras arrancadas forem carregados com a cana. A terra e outras impurezas presentes na cana a ser moída oneram os custos de transporte e manutenção de equipamentos industriais e reduzem a eficiência de moagem e extração de sacarose (VOLPATO, 2001; KROES \& HARRIS, 1996).

A melhoria da qualidade do corte e da matéria-prima é sugerida por meio de intervenções na colheita e em outras práticas culturais existentes, como no preparo do solo, plantio, distância entre sulcos e de mudanças nos projetos das colhedoras (RIDGE, 1980). De acordo com GARSON (1992), os fabricantes de colhedoras estão disponibilizando no mercado sistemas e dispositivos para auxiliar o operador no controle da altura do corte de base. Para o autor, o controle automatizado de altura do mecanismo de corte basal das colhedoras de cana-de-açúcar pode ser um efetivo caminho para reduzir a quantidade de solo presente no suprimento de cana para a indústria.

RIPOLI et al. (2003) avaliaram mecanismo de corte de base flutuante, comparando-o com o cortador de base regular, controlado manualmente em diferentes velocidades. O mecanismo de base flutuante é composto de uma articulação de barras de sustentação de um conjunto de discos cortadores de base, que acompanha a superfície do perfil de solo, com base na força de interação desenvolvida no ponto de contato disco-solo, com o intuito de evitar o corte e o recolhimento de solo durante a operação de colheita. De acordo com os resultados obtidos, o mecanismo, nas condições realizadas pelo estudo, não apresentou vantagens na redução da presença de solo na cana-de-açúcar colhida.

Segundo GARSON \& ARMSTRONG (1993), as outras vantagens do sistema automatizado de controle de altura de corte basal são: redução do consumo de combustível, maior facilidade de operação da colhedora e redução dos danos à base da cana.

Tendo em vista a importância do corte basal na colheita mecanizada para a qualidade da matéria-prima e a longevidade da soqueira, o objetivo deste trabalho é avaliar o desempenho de dispositivo semi-automático de controle de altura de corte basal (DAC), instalado em colhedora automotriz de cana picada.

\section{MATERIAL E MÉTODOS}

Os ensaios foram realizados em duas fazendas de propriedade de uma usina de açúcar e álcool, localizada na região central do Estado de São Paulo, nos dias 15 e 16 de dezembro de 2004. Nos dois dias de avaliação, utilizou-se de uma colhedora automotriz de cana picada, com rodado de esteira, de $243 \mathrm{~kW}$ de potência bruta no motor, com um ano de uso, e equipada com dispositivo semi-automático de controle da altura de corte de base (DAC).

O DAC é composto por transdutores, um controle principal e um programa desenvolvido especialmente para fazer a interface dos dados coletados. Os transdutores recebem as informações das variações da pressão hidráulica dos discos de corte de base e do rolo levantador, ocasionadas pelo contato das lâminas de corte dos discos com o solo e pela entrada da cana cortada. Essa informação é transformada em sinais elétricos, fazendo com que o cortador de base acompanhe automaticamente o microrrelevo do solo. 
A faixa de variação da pressão hidráulica é determinada pelo operador no controlador do DAC, antes de iniciar o trabalho, de acordo com as condições da área a ser colhida. Durante a operação, são realizados ajustes finos na sensibilidade do dispositivo para atender às variações do terreno e da cultura. Quando o DAC permanece desligado, o controle da altura de corte é feito pelo dispositivo regular da colhedora (controle hidráulico manual). As regulagens e manutenções necessárias foram realizadas de acordo com as especificações do fabricante da máquina e da usina, antes da realização dos ensaios.

No dia 15 de dezembro de 2004, a colhedora operou em um talhão de 4,7 ha, em canavial de $6^{0}$ corte, variedade RB 83-5089, espaçamento de 1,4 m, em Latossolo Vermelho-Amarelo de textura média, com declividade de 5\%. No dia 16 de dezembro de 2004, a colhedora foi para outra fazenda e operou em talhão com área de 3,3 ha, declividade de 4\%, Latossolo Vermelho-Amarelo de textura média, em canavial de $2^{2}$ corte, espaçamento de 1,4 m, e variedade SP 80-3280.

Para a caracterização da cultura, foram determinados, a partir da metodologia descrita por RIPOLI et al. (1977), a população de colmos e o porte do canavial. A umidade do solo e a produtividade média dos talhões foram fornecidas pela usina. Foi estabelecida a velocidade média de trabalho para essa avaliação de $5,0 \mathrm{~km} \mathrm{~h}^{-1}$, com a colheita sendo realizada em cana crua.

As avaliações foram realizadas em esquema fatorial com interações entre os fatores período e tecnologia. O período refere-se aos horários de trabalho da colhedora (manhã e tarde) e tecnologia refere-se ao sistema DAC ligado (SL) e desligado (SD). A opção SL ou SD era decidida por meio de sorteio, utilizando nesses dois dias o mesmo operador, com experiência em operar nas duas condições. O operador era avisado do resultado do sorteio (SL ou SD) e iniciava seus trabalhos no período.

A colhedora depositava a cana colhida em dois transbordos com capacidade unitária de $8.000 \mathrm{~kg}$, tracionados por um trator agrícola 4x2 com tração dianteira auxiliar e potência de $89,1 \mathrm{~kW}$. Utilizaram-se quatro transbordos em dois conjuntos, para que a colhedora não precisasse interromper a operação. O operador foi instruído a mudar de tecnologia, ligar ou desligar o sistema, a cada quatro conjuntos de transbordos cheios para a cana de $2^{\circ}$ corte, e a cada cinco conjuntos para o canavial de $6^{0}$ corte, para cada período. Quando o DAC permanecia desligado, o próprio operador controlava a altura pelo dispositivo regular da colhedora (controle hidráulico manual). Após o término do ensaio, em um período de trabalho, o mesmo procedimento se repetia para o próximo.

A qualidade do corte e a qualidade operacional foram avaliadas pela variabilidade da altura de corte, medida pela altura dos tocos das fileiras de cana (ADT), expressa em centímetro $(\mathrm{cm})$, por tocos arrancados e deixados no campo, expressa em percentagem, e pelo teor de impureza mineral presente na matéria-prima colhida, em percentagem.

Durante o processo de colheita e enchimento dos transbordos, os pontos de coleta de ADT eram determinados aleatoriamente, no sentido da fileira de cana cortada pela colhedora, em intervalos de três minutos entre eles, realizando 16 amostras para cada tecnologia (SL, SD) e período (manhã, tarde). Em cada ponto, o palhiço era retirado, medindo-se do nível do solo até o ponto de corte, 20 alturas de tocos, totalizando 320 alturas para cada situação. Utilizou-se de trena graduada com divisão de $0,001 \mathrm{~m}$ para as medições, e na ocorrência de sulco profundo, utilizou-se de régua niveladora para auxiliar a medição.

Durante a medição da ADT, realizou-se a contagem de tocos arrancados e deixados no campo (TA), verificando se os tocos estavam com o sistema radicular totalmente sem aderência ao solo. Em cada amostra de ADT, o TA era quantificado para a análise de sua freqüência para cada parâmetro analisado. $\mathrm{O}$ cálculo da percentagem de TA foi feito pela relação entre o número de TA e o número total de tocos observados durante a medição da ADT.

Os transbordos descarregavam a cana colhida em carretas estacionadas nos carreadores, sendo cada uma carregada com dois transbordos, totalizando quatro carretas para a cana de $2^{-}$corte e cinco para a cana de $6^{\circ}$ corte. Na usina, todas as carretas foram amostradas para a quantificação 
do teor de impurezas minerais (IM), pelo laboratório da empresa. No canavial de segundo corte, o teor médio de IM foi obtido a partir dos valores percentuais das cinco amostras do material colhido e o de $6^{0}$ corte, das seis amostras obtidas das carretas.

A avaliação da variabilidade do corte de base foi efetuada utilizando-se das cartas de controle de médias e de desvio-padrão para a ADT, seguindo-se as metodologias de MONTGOMERY (2004). Considerou-se como limite máximo de especificação de altura de tocos (LE), o padrão adotado pela usina, de $5,0 \mathrm{~cm}$. A partir das cartas de controle, analisou-se a capacidade do processo (CP), do corte de base, seguindo a metodologia de VIEIRA (1999) para o caso de especificação unilateral, altura máxima de corte (LE), de $5,0 \mathrm{~cm}$. Para o cálculo da $\mathrm{CP}$, realizaram-se testes nos valores de ADT para a identificação e a exclusão de dados discrepantes ("outliers"), com a verificação das pressuposições de normalidade e de homogeneidade de variâncias dos dados, utilizando-se do programa estatístico Statistical Analysis System (SAS). Para os casos em que a normalidade e/ou a homogeneidade não foram verificadas, recorreu-se à transformação de dados pelo método potência ótima de Box Cox (SAS INSTITUTE, 2001). Os tocos arrancados foram estudados por estatística descritiva, elaborando-se a frequiência média para cada corte, tecnologia e período analisado. Os teores de impureza mineral foram normalizados com a mesma metodologia descrita para a ADT e calculando-se a média para cada parâmetro analisado.

Efetuou-se a análise comparativa da qualidade operacional para verificar a influência da utilização do DAC na qualidade do corte de base. As variáveis ADT e IM foram estudadas pela análise da variância (ANOVA) e a comparação de médias por meio do teste de Tukey, a 5,0\% de significância, utilizando do programa SAS, levando em conta as possíveis interações entre os fatores tecnologia e período para as variáveis ADT e IM.

\section{RESULTADOS E DISCUSSÃO}

A caracterização dos locais do ensaio mostrou que, no talhão de segundo corte, a umidade do solo foi de $13,5 \%$, o porte foi classificado como deitado e a população foi de 14,1 colmos m ${ }^{-1}$, com produtividade média de $110 \mathrm{t} \mathrm{ha}^{-1}$. No canavial de $6^{\circ}$ corte, a umidade do solo foi de $9,6 \%$, o porte

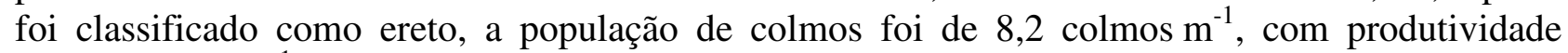
média de $60 \mathrm{t} \mathrm{ha}^{-1}$.

Nas Figuras 1 e 2, indica-se que, mesmo com um operador treinado e experiente e com o uso do DAC, não foi possível manter o processo sob controle, com vários pontos fora dos limites estatísticos, indicando que causas atribuíveis estão atuando no sistema durante os períodos. As causas atribuíveis podem estar ligadas ao funcionamento do DAC, ao operador e ao sistema de produção da cana (preparo do solo, plantio e condução da cultura).

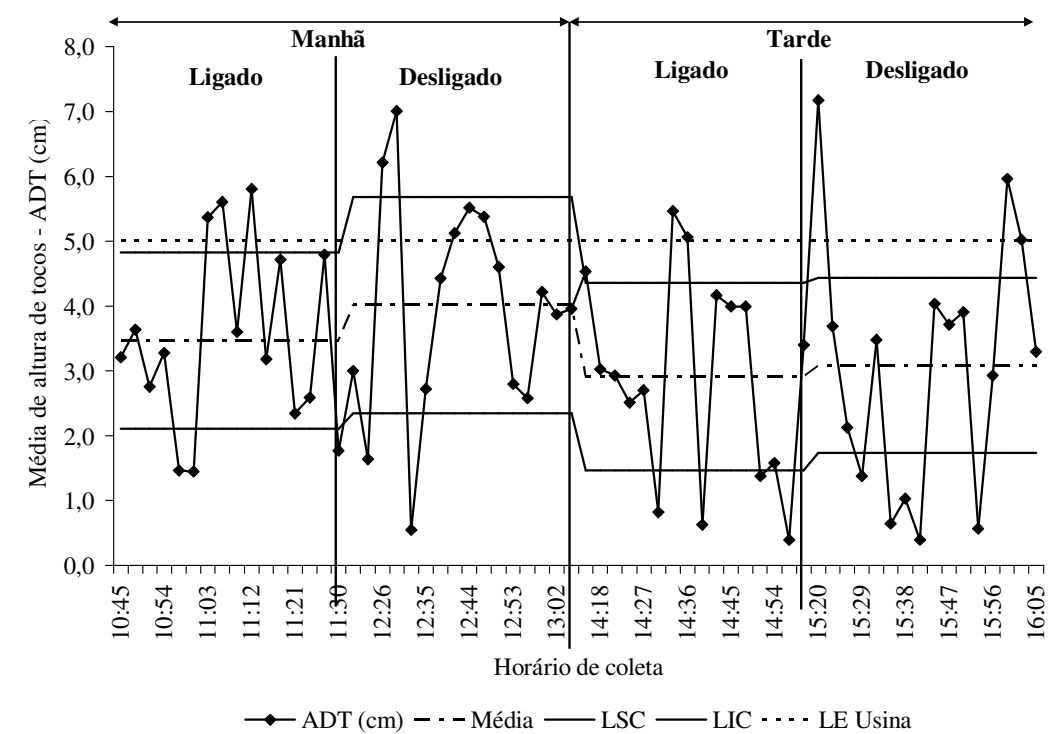

ADT: altura de tocos; LSC: limite superior de controle; LIC: limite inferior de controle; LE: limite de especificação.

FIGURA 1. Carta de controle para médias de altura de tocos (ADT) em canavial de $2^{\circ}$ corte. 


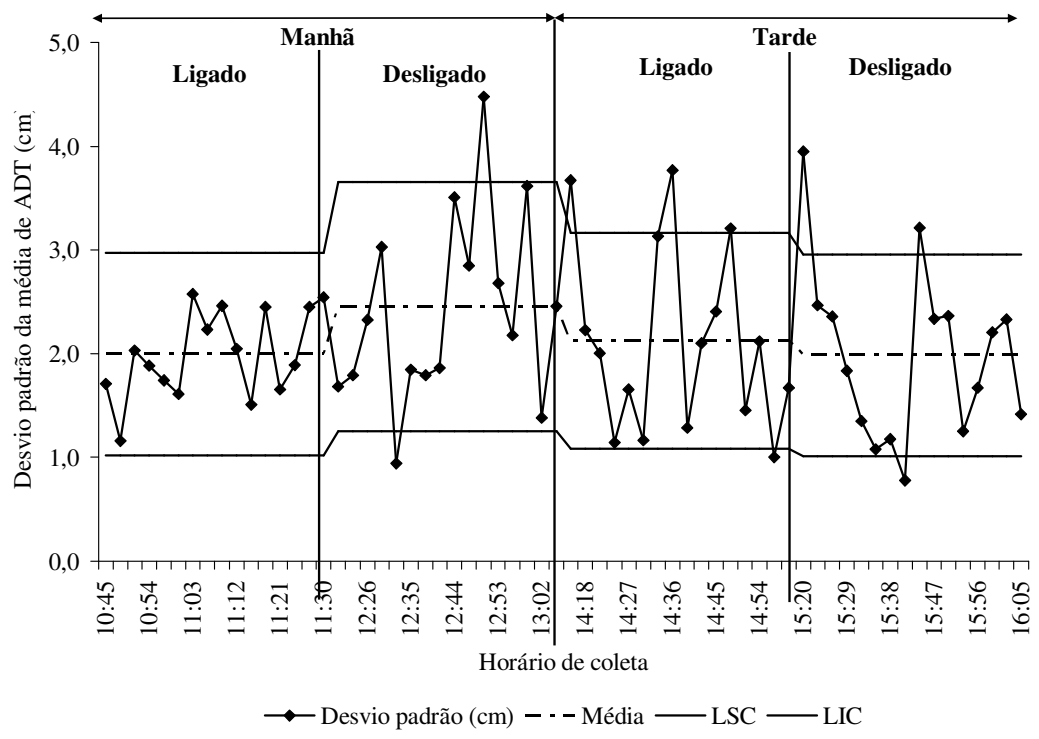

LSC: limite superior de controle; LIC: limite inferior de controle.

FIGURA 2. Carta de controle do desvio-padrão da média de ADT em canavial de $2^{\circ}$ corte.

No período da manhã, o DAC ligado mostra menor variabilidade no corte de base, e os limites de controle estatístico da média de ADT estão dentro do LE da usina, enquanto com o DAC desligado, com operação manual, ocorre aumento da média de ADT, e o limite superior de controle (LSC) está acima do LE da usina. Destaca-se que, no período da manhã, com o uso do DAC ligado, os pontos de média de ADT que apresentam valores menores ou iguais a 3,0 cm, estavam em sulcos profundos com camalhão (Figura 1). O desvio-padrão da média de ADT com o DAC ligado está sob controle estatístico, com todos os pontos dentro dos limites de controle, enquanto com o DAC desligado, o desvio-padrão é superior em $0,5 \mathrm{~cm}$ em relação ao DAC ligado, apresentando pontos fora dos limites de controle (Figura 2).

No período da tarde, a média de ADT com o DAC ligado é $0,2 \mathrm{~cm}$ inferior, no entanto o desvio-padrão da média de ADT para o dispositivo ligado é $0,1 \mathrm{~cm}$ superior. Nas duas tecnologias desse período, os limites de controle estatístico encontram-se abaixo do LE da usina (Figuras 1 e 2). No período da tarde, não foram encontrados sulcos profundos nas amostras. Verificou-se que a frequiência de ADT com corte na classe de 0 a $1 \mathrm{~cm}$ está presente em maior quantidade nos pontos de médias de ADT menores que 1,2 cm com o DAC desligado, no período da manhã, e ligado à tarde. Esse tipo de corte pode, em algumas situações, incorporar terra com a matéria-prima colhida devido ao possível contato das facas com o solo, que acelera o desgaste devido à abrasão, diminuindo a qualidade do corte.

Nas Figuras 3 e 4, mostram-se as cartas de controle do processo para médias de ADT e desvio-padrão para o canavial de $6^{0}$ corte. Em linhas gerais, o processo de corte de base não está sob controle para nenhum dos períodos avaliados, indicando que causas atribuíveis atuam no processo. A operação, com o DAC ligado ou desligado, não consegue atuar de modo a superar as causas atribuíveis, embora o sistema semi-automático tenha trabalhado com o limite superior de controle (LSC) abaixo do limite solicitado pela usina de $5,0 \mathrm{~cm}$. Já a operação manual (DAC desligado) igualou ou ficou acima do limite da usina nos dois períodos.

As causas atribuíveis podem ser as mesmas citadas no caso do canavial de $2^{\mathrm{o}}$ corte, com o acréscimo de infestação de plantas daninhas, com maior intensidade na área trabalhada no período da tarde. Nos dois períodos, a variabilidade do corte diminui quando o DAC foi ligado, observado pela menor amplitude dos limites de controle estatístico, o que auxilia na redução da média de ADT. Verificou-se que a freqüência de ADT com corte na classe de 0 a $1 \mathrm{~cm}$ está presente em maior quantidade nos pontos de médias de ADT menores que $1,0 \mathrm{~cm}$, no período da tarde com o DAC ligado. Na Figura 4, a média do desvio-padrão de ADT, com a utilização do DAC ligado, é inferior em $0,1 \mathrm{~cm}$ no período da manhã e $0,5 \mathrm{~cm}$ no período da tarde, em relação ao obtido com o 
DAC desligado. No entanto, no período da tarde, em operação manual, com o DAC desligado, o desvio-padrão encontra-se em controle estatístico, com todos os pontos dentro dos limites.

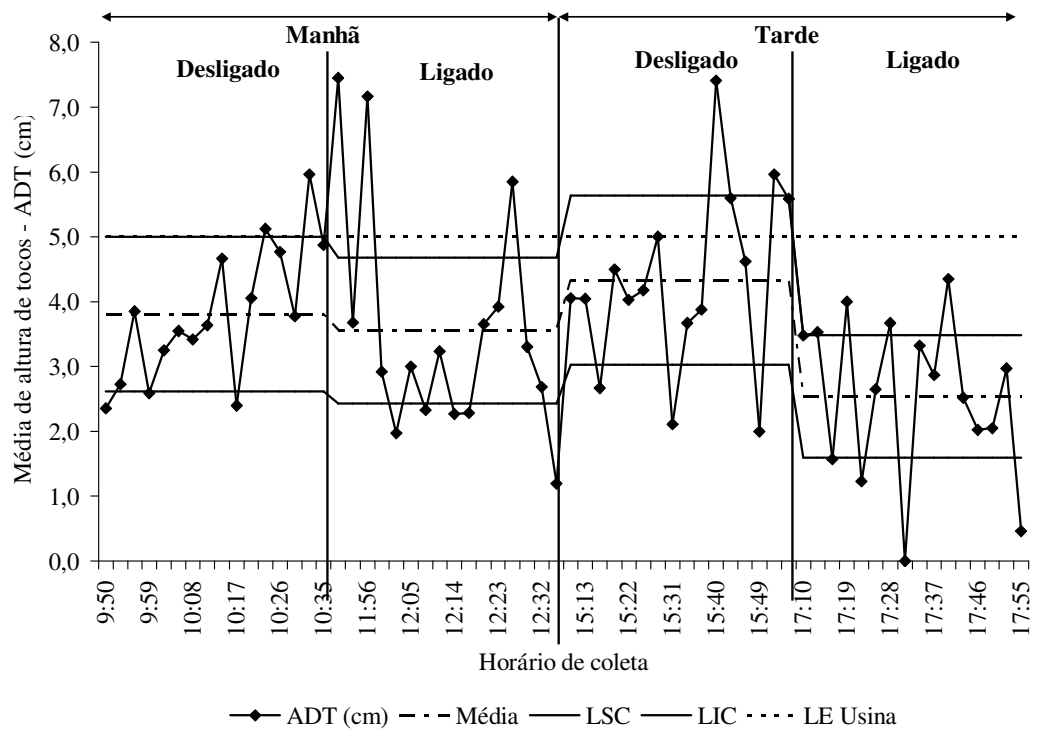

ADT: altura de tocos; LSC: limite superior de controle; LIC: limite inferior de controle; LE: limite de especificação.

FIGURA 3. Carta de controle para médias de altura de tocos (ADT) em canavial de $6^{ }$corte.

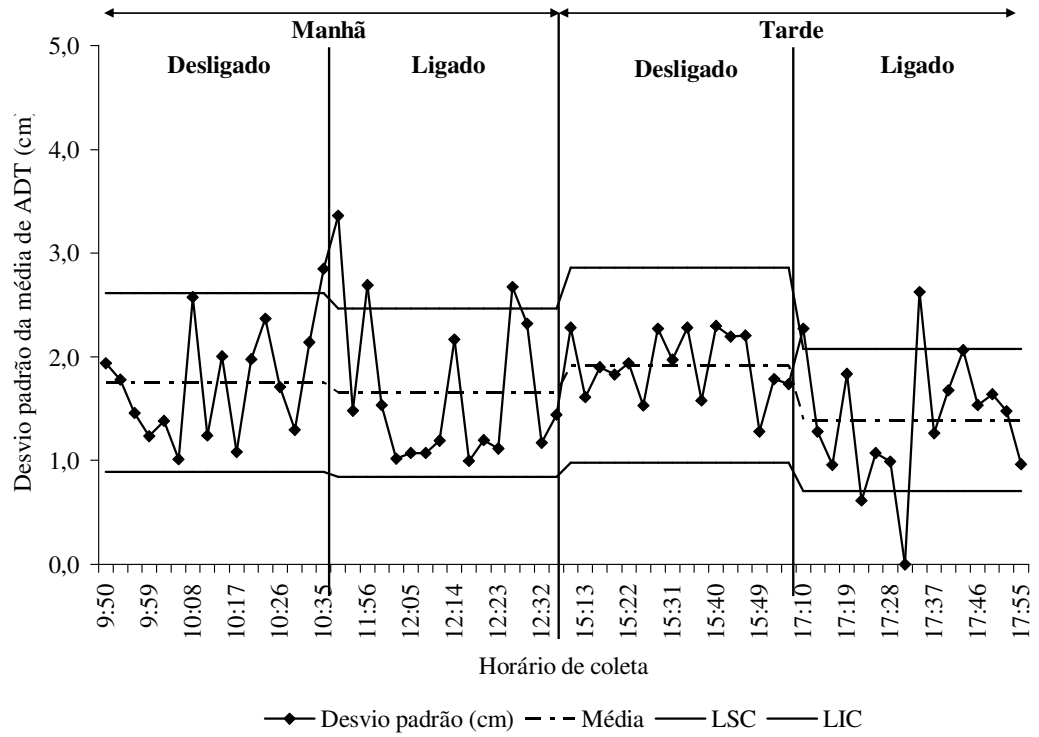

LSC: limite superior de controle; LIC: limite inferior de controle.

FIGURA 4. Carta de controle do desvio-padrão da média de ADT em canavial de $6^{\circ}$ corte.

No cálculo do índice de capacidade do processo para os dois cortes analisados (Tabela 1), pode-se verificar que, em todos os casos, independentemente do corte e dos parâmetros analisados, o processo de corte de base não tem condições de manter a altura de corte especificada pela usina, de $5 \mathrm{~cm}$. No segundo corte, com a variabilidade existente, a usina teria de adotar valor de LE mínimo de $11,4 \mathrm{~cm}$ para o DAC ligado, e de $14,1 \mathrm{~cm}$ para o DAC desligado. Para o $6^{\circ}$ corte, o valor de adequação seria de $9,3 \mathrm{~cm}$ para o dispositivo ligado, e de $14,2 \mathrm{~cm}$ para o DAC desligado. Os maiores valores de CP e os menores de LE para adequação foram, no $6^{\underline{0}}$ corte, com o sistema ligado nos períodos da manhã e da tarde. Para manter o LE utilizado pela usina $(5 \mathrm{~cm})$, é necessário reduzir a variabilidade do corte de base, mostrado pela amplitude dos limites estatísticos das cartas de controle. 
TABELA 1. Índice de capacidade do processo (CP), classificação e valor mínimo do limite de especificação (LE) para a adequação do processo para os parâmetros analisados.

\begin{tabular}{|c|c|c|c|c|c|c|c|}
\hline \multicolumn{4}{|c|}{$2^{0}$ Corte } & \multicolumn{4}{|c|}{$6^{\circ}$ Corte } \\
\hline Manhã & $\mathrm{CP}$ & Classificação & LE Mínimo $(\mathrm{cm})$ & Manhã & $\mathrm{CP}$ & Classificaçãc & LE Mínimo (cm) \\
\hline DAC ligado & 0,36 & Inadequado & 10,2 & DAC ligado & 0,41 & Inadequado & 8,8 \\
\hline DAC desligado & 0,13 & Inadequado & 14,1 & DAC desligado & 0,23 & Inadequado & 14,2 \\
\hline Tarde & & & & Tarde & & & \\
\hline DAC ligado & 0,30 & Inadequado & 11,4 & DAC ligado & 0,47 & Inadequado & 9,3 \\
\hline DAC desligado & 0,25 & Inadequado & 12,0 & DAC desligado & 0,13 & Inadequado & 12,0 \\
\hline
\end{tabular}

Quanto ao percentual de tocos arrancados e deixados no campo, na Tabela 2, mostra-se que, no segundo corte, a maior frequiência de tocos arrancados e deixados no campo foi na condição em que o sistema de corte basal foi operado manualmente, com o DAC desligado, independentemente do período analisado. Na operação manual, ocorreram as maiores oscilações de médias e de desviopadrão de ADT ao longo do tempo de avaliação e valores médios de desvio-padrão superiores, com exceção do $2^{-}$corte, no período da tarde, com desvio-padrão médio $0,1 \mathrm{~cm}$ menor em comparação com o DAC ligado, no mesmo período (Figuras 1 e 2). Os tocos arrancados reduzem a longevidade do canavial e, se forem incorporados com a matéria-prima colhida, podem aumentar o teor de impureza mineral (IM).

TABELA 2. Percentual de tocos arrancados e deixados no campo em $2^{\underline{0}}$ e $6^{\underline{0}}$ cortes.

\begin{tabular}{|c|c|c|c|c|c|c|c|}
\hline \multirow{2}{*}{$2^{\circ}$ Corte } & \multicolumn{3}{|c|}{ Percentual de Tocos Arrancados } & \multirow{2}{*}{$6^{-}$Corte } & \multicolumn{3}{|c|}{ Percentual de Tocos Arrancados } \\
\hline & \multicolumn{2}{|c|}{ DAC } & \multirow{2}{*}{$\begin{array}{l}\text { Média } \\
\text { Período }\end{array}$} & & \multicolumn{2}{|c|}{ DAC } & \multirow{2}{*}{$\begin{array}{l}\text { Média } \\
\text { Período }\end{array}$} \\
\hline Período & Ligado & Desligado & & Período & Ligado & Desligado & \\
\hline Manhã & 0,0 & 0,3 & 0,2 & Manhã & 2,8 & 4,4 & 3,6 \\
\hline Tarde & 0,9 & 6,6 & 3,8 & Tarde & 0,6 & 3,1 & 1,9 \\
\hline Média DAC & 0,5 & 3,5 & & Média DAC & 1,7 & 3,8 & \\
\hline
\end{tabular}

Para o $6^{0}$ corte, na Tabela 2 , mostra-se que a maior freqüência de tocos arrancados e deixados no campo foi nas condições em que o sistema de corte basal foi operado manualmente, com o DAC desligado, independentemente do período analisado. $\mathrm{Na}$ operação manual, ocorreram maiores oscilações de médias de ADT ao longo do tempo de avaliação e valores médios de desvio-padrão superiores (Figuras 3 e 4 ).

Na comparação das médias de ADT e de IM, entre as tecnologias de corte de base em relação ao período de trabalho no canavial de $2^{\underline{0}}$ corte (Tabela 3 ), observa-se que não ocorreram diferenças significativas para os dois períodos em termos da altura de corte do toco para o sistema, operando com o DAC ligado e desligado. O dispositivo desligado obteve melhor resultado quanto às impurezas minerais carregadas para a usina. Os valores obtidos foram de 1,3\% ligado e 0,6\% desligado, no período da manhã, diferença significativa de $0,7 \%$. O valor de IM para o DAC ligado no período da manhã $(1,3 \%)$ pode ser explicado pelo fato de alguns pontos amostrados de média de ADT (médias menores ou iguais a 3,0 cm, Figura 1) estarem em sulcos profundos com camalhão. As lâminas dos discos do corte-base, nessas condições, entram em contato com o solo, contaminando a matéria-prima colhida com terra, elevando o teor de IM. No período da tarde, os valores de IM não estão disponíveis, pois as carretas não foram analisadas pela usina.

TABELA 3. Comparação das médias de altura de tocos (ADT) e impureza mineral (IM) entre tecnologias de corte basal em relação ao período de trabalho, em $2^{\circ}$ corte.

\begin{tabular}{|c|c|c|c|c|c|c|c|c|c|}
\hline \multicolumn{5}{|c|}{ Média de ADT $(\mathrm{cm})$} & \multicolumn{5}{|c|}{ Média de IM (\%) } \\
\hline \multicolumn{2}{|c|}{ DAC } & \multirow{2}{*}{ Período } & \multirow{2}{*}{$\operatorname{Pr}>\mathrm{T}$} & \multirow{2}{*}{ Resultados } & \multicolumn{2}{|c|}{ DAC } & \multirow{2}{*}{ Período } & \multirow{2}{*}{$\mathrm{PR}>\mathrm{T}$} & \multirow{2}{*}{ Resultados } \\
\hline Desligado & Ligado & & & & Desligado & Ligado & & & \\
\hline 4,0 & 3,5 & Manhã & 0,1921 & n.s. & 0,56 & 1,29 & Manhã & 0,0001 & *** \\
\hline 3,1 & 2,9 & Tarde & 0,5112 & n.s. & $\ldots$ & $\ldots$ & Tarde & $\ldots$ & $\ldots$ \\
\hline
\end{tabular}

n.s.: diferença não-significativa estatisticamente; $* *$ : diferença estatística com confiança de $99 \%$; ...: dado numérico não-disponível 
A comparação das médias de ADT e IM entre períodos, no segundo corte (Tabela 4), revela que existem diferenças quanto à altura de corte de base quanto ao período de trabalho. No período da tarde, o corte foi realizado em altura menor, com o DAC em uso ou não. A impureza mineral com o DAC ligado, no período da manhã, foi de $1,3 \%$, ante $0,8 \%$ no período da tarde, com diferença significativa.

TABELA 4. Comparação das médias de altura de tocos (ADT) e impureza mineral (IM) entre períodos de trabalho em relação à tecnologia de corte basal utilizada, em $2^{\underline{0}}$ corte.

\begin{tabular}{|c|c|c|c|c|c|c|c|c|c|}
\hline \multicolumn{5}{|c|}{ Média de ADT $(\mathrm{cm})$} & \multicolumn{5}{|c|}{ Média de IM $(\%)$} \\
\hline \multicolumn{2}{|c|}{ Período } & \multirow{2}{*}{ DAC } & \multirow{2}{*}{$\operatorname{Pr}>\mathrm{T}$} & \multirow{2}{*}{$\begin{array}{c}\text { Resultados } \\
\text { Manhã }\end{array}$} & \multicolumn{2}{|c|}{ Período } & \multirow{2}{*}{ DAC } & \multirow{2}{*}{$\mathrm{PR}>\mathrm{T}$} & \multirow{2}{*}{ Resultados } \\
\hline Manhã & Tarde & & & & Manhã & Tarde & & & \\
\hline 4,0 & 3,1 & Desligado & 0,0001 & $* *$ & $\ldots$ & $\ldots$ & Desligado & $\ldots$ & ... \\
\hline 3,5 & 2,8 & Ligado & 0,0007 & $* *$ & 1,29 & 0,80 & Ligado & 0,0001 & $* *$ \\
\hline
\end{tabular}

...: dado numérico não-disponível; **: diferença estatística com confiança de $99 \%$.

Na comparação das médias de ADT e IM entre tecnologias de corte basal em relação ao período de trabalho, no canavial de $6^{-}$corte (Tabela 5), observa-se que, estatisticamente, houve diferença na altura de corte entre a operação com o sistema ligado e desligado, com o DAC cortando em altura menor do que a operação manual. No caso das impurezas minerais, não ocorreram diferenças significativas mesmo com o DAC operando em altura inferior à operação manual.

TABELA 5. Comparação das médias de altura de tocos (ADT) e impureza mineral (IM) entre tecnologias de corte basal em relação ao período de trabalho, em $6^{\underline{0}}$ corte.

\begin{tabular}{|c|c|c|c|c|c|c|c|c|c|}
\hline \multicolumn{5}{|c|}{ Média de ADT $(\mathrm{cm})$} & \multicolumn{5}{|c|}{ Média de IM (\%) } \\
\hline \multicolumn{2}{|c|}{ DAC } & \multirow{2}{*}{ Período } & \multirow{2}{*}{$\operatorname{Pr}>\mathrm{T}$} & \multirow{2}{*}{ Resultado } & \multicolumn{2}{|c|}{ DAC } & \multirow{2}{*}{ Período } & \multirow{2}{*}{$\mathrm{PR}>\mathrm{T}$} & \multirow{2}{*}{ Resultados } \\
\hline Desligado & Ligado & & & & Desligado & Ligado & & & \\
\hline 3,8 & 3,5 & Manhã & 0,0281 & $*$ & 1,47 & 0,67 & Manhã & 0,0546 & n.s. \\
\hline 4,3 & 2,5 & Tarde & 0,0001 & $* *$ & 0,30 & 0,33 & Tarde & 0,8044 & n.s \\
\hline
\end{tabular}

*: diferença estatística com confiança de 95\%; **: diferença estatística com confiança de 99\%; n.s.: diferença nãosignificativa estatisticamente.

Na comparação das médias de ADT e IM entre períodos de trabalho em relação à tecnologia de corte de base utilizada, no canavial de $6^{0}$ corte (Tabela 6 ), observa-se que o corte foi realizado em altura inferior no período da tarde com o uso do DAC, enquanto com o dispositivo desligado, a ADT se eleva no período da tarde. A altura de corte maior para o sistema de corte de base operado manualmente pode estar ligada à infestação de capim braquiária (Brachiaria plantagynea) no canavial, fazendo com que o operador, por falta de visibilidade, realizasse o corte em altura superior para evitar o contato das lâminas dos discos de corte de base com o solo. Esse comportamento pode ser observado nas cartas de controle das Figuras 3 e 4, em que mais da metade das médias das amostras de ADT são superiores a 3,0 cm, e 2,2\% dos tocos analisados tiveram corte no nível do solo, enquanto com o DAC ligado, no mesmo período, apresentou 19,1\% dos tocos analisados na classe de 0,0 a 1,0 cm. É importante ressaltar que o índice de impurezas para o sistema operado manualmente foi menor no período da tarde, enquanto com o DAC ligado, não existiram diferenças entre os períodos.

TABELA 6. Comparação das médias de altura de tocos (ADT) e impureza mineral (IM) entre períodos de trabalho em relação à tecnologia de corte de base utilizada, em $6^{0}$ corte.

\begin{tabular}{|c|c|c|c|c|c|c|c|c|c|}
\hline \multicolumn{5}{|c|}{ Média de ADT $(\mathrm{cm})$} & \multicolumn{5}{|c|}{ Média de IM (\%) } \\
\hline \multicolumn{2}{|c|}{ Período } & \multirow{2}{*}{ DAC } & \multirow{2}{*}{$\operatorname{Pr}>\mathrm{T}$} & \multirow{2}{*}{$\begin{array}{l}\text { Resultados } \\
\text { Manhã }\end{array}$} & \multicolumn{2}{|c|}{ Período } & \multirow{2}{*}{$\mathrm{DAC}$} & \multirow{2}{*}{$\mathrm{PR}>\mathrm{T}$} & \multirow{2}{*}{ Resultados } \\
\hline Manhã & Tarde & & & & Manhã & Tarde & & & \\
\hline 3,8 & 4,3 & Desligado & 0,0077 & $*$ & 1,47 & 0,30 & Desligado & 0,0001 & ** \\
\hline 3,5 & 2,5 & Ligado & 0,0001 & $* *$ & 0,43 & 0,33 & Ligado & 0,2133 & n.s. \\
\hline
\end{tabular}

*: diferença estatística com confiança de $95 \%$; **: diferença estatística com confiança de 99\%; n.s.: diferença nãosignificativa estatisticamente. 


\section{CONCLUSÕES}

O corte de base, com e sem uso do DAC, não está sob controle estatístico de processo e não tem condições de manter a altura de corte especificada pela usina. Existem diferenças na altura do toco (ADT) e no índice de impureza quando se considera o período de trabalho, independentemente do uso do DAC. O dispositivo pode ser útil para a manutenção de altura de corte menor, mas foi influenciado pelo estado do canavial. Para o canavial de $6^{\underline{0}}$ corte de porte ereto, o DAC influenciou, mas, no canavial de $2^{-}$corte de porte deitado, não ocorreu influência. A utilização do DAC não trouxe vantagens quanto à impureza mineral, no entanto apresentou freqüência inferior de tocos arrancados.

\section{REFERÊNCIAS}

GARSON, C.A. Control of harvester base cutter height. Proceedings of Australian Society of Sugar CaneTechnologists, Towsville, v.1, n.1, p.156-62, 1992.

GARSON, C.A.; ARMSTRONG, M. Ultrasonic base cutter height control: a report on 1992 season experiments. Proceedings of Australian Society of Sugar Cane Technologists, Bundaberg, v.1, n.1, p. 52-9, 1993.

KROES, S.; HARRIS, H.D. Knockdown causes major damage to cane during harvesting. Proceedings of Australian Society of Sugar Cane Technologists, Brisbane, v.1, n.2, p.137-44, 1996.

MONTGOMERY, D.C. Introdução ao controle estatístico da qualidade. 4.ed. Rio de Janeiro: LTC, 2004. 514 p.

NUNES JUNIOR, D.; PINTO, R.S.A.; KIL, R.A. Indicadores de desempenho da agroindústria canavieira: safra 2003-2004. Ribeirão Preto: IDEA, 2005. 195 p.

RIDGE, D.R. Minimizing the problem of soil in chopper harvester cane. Proceedings of International Society of Sugar Cane Technologists, Manila, v.2, n.1, p.315-23, 1980.

RIPOLI, T.C.C.; MIALHE, L.G.; NOVAES, H.P. Um critério para avaliação de canaviais visando à colheita. In: CONGRESSO BRASILEIRO DE ENGENHARIA AGRÍCOLA, 4., 1977, Pelotas. Separata ... Pelotas: Sociedade Brasileira de Engenharia Agrícola, 1977. 10 p.

RIPOLI, M.L.C.; RIPOLI, T.C.C.; OLIVEIRA, M.A. Evalution of two different base cutters in green cane mechanical harvest. In: ASAE ANNUAL INTERNATIONAL MEETING, 2003, Las Vegas. Proceedings... St. Joseph: ASAE, 2003. (Paper, 031015).

SAS INSTITUTE. SAS/STAT: guide for personal computers. $8^{\text {th }}$ ed. Cary: SAS Institute, 2001. $943 \mathrm{p}$.

VIEIRA, S. Estatística para a qualidade: como avaliar com precisão a qualidade em produtos e serviços. Rio de Janeiro: Campus, 1999. 198 p.

VOLPATO, J.L.M. Otimização de um cortador de base flutuante para seguimento do perfil de solo em colhedoras de cana-de-açúcar. 2001. 204 f. Tese (Doutorado em Máquinas Agrícolas) Faculdade de Engenharia Agrícola, Universidade Estadual de Campinas, Campinas, 2001. 